\title{
Proxy-Reported Health-Related Quality of Life of Patients With Juvenile Idiopathic Arthritis: The Pediatric Rheumatology International Trials Organization Multinational Quality of Life Cohort Study
}

\author{
SHEILA OLIVEIRA, ${ }^{1}$ ANGELO RAVELLI, ${ }^{1}$ ANGELA PISTORIO, ${ }^{2}$ ESTEBAN CASTELL, ${ }^{1}$ \\ CLARA MALATTIA, ${ }^{1}$ ANNE MARIE PRIEUR, ${ }^{3}$ CLAUDIA SAAD-MAGALHÃES, ${ }^{4}{ }^{K E V I N ~ J . ~ M U R R A Y, ~}{ }^{5}$ \\ SANG-CHEOL BAE, ${ }^{6}$ RIK JOOS, ${ }^{7}$ IVAN FOELDVARI, ${ }^{8}$ CAROLINA DUARTE-SALAZAR, ${ }^{9}$ \\ NICO WULFFRAAT, ${ }^{10}$ PEKKA LAHDENNE, ${ }^{11}$ PAVLA DOLEZALOVA,,${ }^{12}$ JAIME DE INOCENCIO,,${ }^{13}$ \\ FLORENCE KANAKOUDI-TSAKALIDOU, ${ }^{14}$ MICHAEL HOFER,${ }^{15}$ IRINA NIKISHINA, ${ }^{16}$ \\ HURI OZDOGAN, ${ }^{17}$ PHILIP J. HASHKES, ${ }^{18}$ JEANNE M. LANDGRAF,${ }^{19}$ ALBERTO MARTINI, ${ }^{20}$ AND \\ NICOLINO RUPERTO, ${ }^{1}$ FOR THE PEDIATRIC RHEUMATOLOGY INTERNATIONAL TRIALS \\ ORGANIZATION (PRINTO)
}

Objective. To investigate the proxy-reported health-related quality of life (HRQOL) and its determinants in patients with juvenile idiopathic arthritis (JIA).

Methods. In this multinational, multicenter, cross-sectional study, HRQOL of patients with JIA was assessed through the Child Health Questionnaire (CHQ) and was compared with that of healthy children of similar age from the same geographic area. Potential determinants of HRQOL included demographic data, physician's and parent's global assessments, measures of joint inflammation, Childhood Health Assessment Questionnaire (CHAQ), and erythrocyte sedimentation rate.

Results. A total of 6,639 participants $(3,324$ with JIA and 3,315 healthy) were enrolled from 32 countries. The mean \pm SD physical and psychosocial summary scores of the CHQ were significantly lower in patients with JIA than in healthy children (physical: $44.5 \pm 10.6$ versus $54.6 \pm 4.0, P<0.0001$; psychosocial: $47.6 \pm 8.7$ versus $51.9 \pm 7.5, P<0.0001$ ), with the physical well-being domain being most impaired. Patients with persistent oligoarthritis had better HRQOL compared with other subtypes, whereas HRQOL was similar across patients with systemic arthritis, polyarthritis, and extended oligoarthritis. A CHAQ score $>1$ and a pain intensity rating $>3.4 \mathrm{~cm}$ on a $10-\mathrm{cm}$ visual analog scale were the strongest determinants of poorer HRQOL in the physical and psychosocial domains, respectively.

Conclusion. We found that patients with JIA have a significant impairment of their HRQOL compared with healthy peers, particularly in the physical domain. Physical well-being was mostly affected by the level of functional impairment, whereas the intensity of pain had the greatest influence on psychosocial health.

KEY WORDS. Health-related quality of life; Juvenile idiopathic arthritis; Disability.

\section{INTRODUCTION}

The assessment of children with juvenile idiopathic arthritis (JIA) has been traditionally focused on disease-centered outcomes, such as disease activity, clinical remission, ar-

Supported by a grant from the European Union (BMH4983531 CA and AML/B7-311/97/0666/II-0246-FI).

${ }^{1}$ Sheila Oliveira, MD (current address: Instituto de Puericultura e Pediatria Martagao Gesteira, Rio de Janeiro, Brazil), ticular and extraarticular damage, and results of laboratory indicators of systemic inflammation (1-3). Because JIA influences virtually all aspects of the child's life and his or her family (4), it is increasingly recognized that a complete

Angelo Ravelli, MD, Esteban Castell, MD, Clara Malattia, MD, Nicolino Ruperto, MD, MPH: IRCCS G. Gaslini, Pediatria II, Reumatologia, Pediatric Rheumatology International Trials Organization, Genoa, Italy; ${ }^{2}$ Angela Pistorio, MD, PhD: IRCCS G. Gaslini, Servizio di Epidemiologia e Biosta- 
assessment of the disease requires the evaluation of healthrelated quality of life (HRQOL), which is a multidimensional concept that incorporates measures of physical symptoms, functional status, and disease impact on psychological and social functioning $(5,6)$.

In recent years, a number of HRQOL measures have been developed for use in children and are usually divided into 2 types: disease-specific measures (4-11), which are centered on a particular disease such as JIA, and generic, which measure quality of life independent of the underlying disease $(12,13)$. However, only a few of these measures are available in several languages $(12,13)$, and for this reason the researchers of the Pediatric Rheumatology International Trials Organization (PRINTO) (14) have elected to cross-culturally adapt and validate the American English parent version of the Childhood Health Assessment Questionnaire (CHAQ) (9) and the Child Health Questionnaire (CHQ) (12) into several languages $(15,16)$ according to existing guidelines (17). The CHAQ is a JIA diseasespecific instrument selected because of its widespread use in the pediatric rheumatology literature and ease of administration and scoring, and the CHQ was chosen because it can be used for all other pediatric rheumatic diseases.

The purpose of the present study, conducted by PRINTO (14), was to examine the proxy-reported HRQOL of a large cohort of children with JIA enrolled in 32 countries worldwide, to compare the results with those obtained in healthy peers from the same geographic area, and to iden-

tistica, Genoa, Italy; ${ }^{3}$ Anne Marie Prieur, MD: Hôpital Necker Enfants Malades, Paris, France; ${ }^{4}$ Claudia SaadMagalhães, MD: Universidade Estadual Paulista, Botucatu, Brazil; ${ }^{5}$ Kevin J. Murray, MB, BS, FRACP: Princess Margaret Hospital for Children, Perth, Australia; ${ }^{6}$ Sang-Cheol Bae, MD, PhD: Hospital for Rheumatic Diseases, Hanyang University Medical Center, Seoul, Korea; ${ }^{7}$ Rik Joos, MD: Universitair Ziekenhuis Gent, Centrum Voor Kinderreumatologie, Ghent, Belgium; ${ }^{8}$ Ivan Foeldvari, MD: Allgemeines Krankenhaus Eilbeck, Hamburg, Germany; ${ }^{9}$ Carolina DuarteSalazar, MD: Instituto Nacional de Rehabilitación, Tlalpan Mexico DF, Mexico; ${ }^{10}$ Nico Wulffraat, MD: Wilhelmina Kinderziekenhuis, Utrecht, The Netherlands; ${ }^{11}$ Pekka Lahdenne, MD: Hospital for Children and Adolescents, Helsinki University Central Hospital, Helsinki, Finland; ${ }^{12}$ Pavla Dolezalova, MD, PhD: 1st Faculty of Medicine and General Faculty Hospital, Prague, Czech Republic; ${ }^{13}$ Jaime de Inocencio, MD: CS Estrecho de Corea, Instituto Madrileño de la Salud, Madrid, Spain; ${ }^{14}$ Florence Kanakoudi-Tsakalidou, MD: Aristotle University of Thessaloniki, Ippokration General Hospital, Thessalonika, Greece; ${ }^{15}$ Michael Hofer, MD: Pédiatrie, Lausanne, and Hôpitaux Universitaires de Genève, Pédiatrie, Geneva, Switzerland; ${ }^{16}$ Irina Nikishina, MD: Institute of Rheumatology RAMS, Moscow, Russia; ${ }^{17}$ Huri Ozdogan, MD: Cerrahpasa Tip Fakultesi, Istanbul, Turkey; ${ }^{18}$ Philip J. Hashkes, MD, MSc: Cleveland Clinic Foundation, Cleveland, Ohio; ${ }^{19}$ Jeanne M. Landgraf, MA: HealthActCHQ, Boston, Massachusetts; ${ }^{20}$ Alberto Martini, MD: IRCCS G. Gaslini, Pediatria II, Università degli Studi, Genoa, Italy.

Address correspondence to Nicolino Ruperto, MD, MPH, Pediatric Rheumatology International Trials Organization, IRCCS G. Gaslini, Università di Genova, Pediatria II - Reumatologia, Largo Gaslini, 5, 16147 Genoa, Italy. E-mail: nicolaruperto@ospedale-gaslini.ge.it.

Submitted for publication December 23, 2005; accepted in revised form April 18, 2006. tify the factors that have the greatest influence on a child's HRQOL. The overall hypothesis was that JIA would be affected more in the physical component rather than in the psychosocial component and that the variables classically used to evaluate response to therapy in JIA $(18,19)$ could also be important as clinical determinants for poor HRQOL.

\section{PATIENTS AND METHODS}

Study design, patients, and healthy children. Patients and healthy children were enrolled by the PRINTO members from April 1998 to March 2000. Inclusion criteria for patients were a diagnosis of JIA by the International League of Associations for Rheumatology (ILAR) criteria (20) and $\leq 18$ years of age at the time of the evaluation. Patients with psoriatic arthritis and enthesitis-related arthritis were excluded from the analysis because the number of patients with these diseases was too small. Healthy children were either students in local schools or healthy sisters/brothers of the patients with JIA. In each center, written or verbal informed consent was obtained from a parent or legal guardian and the patient if of appropriate age, according to the requirements of the local ethic committees.

HRQOL assessment. The national language version of the parent-administered 50-item version of the CHQ (also called CHQ PF-50) $(12,15,16)$ was used to assess HRQOL of patients and healthy children. The CHQ is a generic selfadministered instrument designed to capture the physical, emotional, and social components of health status of children 5-18 years of age and comprises 15 health concepts (range 0-100): global health, physical functioning, role social limitations (emotional/behavioral), role social limitations (physical), bodily pain/discomfort, behavior, general behavior, mental health, self-esteem, general health perception, change in health, parent impact (emotional), parent impact (time), family activities, and family cohesion. In addition, there are 2 summary measures based on US normative standard: the physical summary score (PhS) and the psychosocial summary score (PsS; a mean \pm SD of $50 \pm 10)$. Higher scores in the scales indicate better HRQOL (12).

Functional ability assessment. A parent of each patient was asked to complete the national language version of the CHAQ $(9,15,16)$. The CHAQ measures the child's ability to perform functions included in 8 areas of daily living, which are averaged to calculate the CHAQ disability index (range 0 [best] to 3 [worst]). The parent's version of the CHAQ incorporates a double-anchored horizontal $10-\mathrm{cm}$ visual analog scale (VAS) for the assessment of the child's overall well-being (with anchors of 0 [very well] and 10 [very poor]) and a double-anchored horizontal 10-cm VAS for the assessment of the intensity of the child's pain (with anchors of 0 [no pain] and 10 [very severe pain]).

Assessment of JIA severity measures. The following measures of JIA severity were assessed in each patient by 


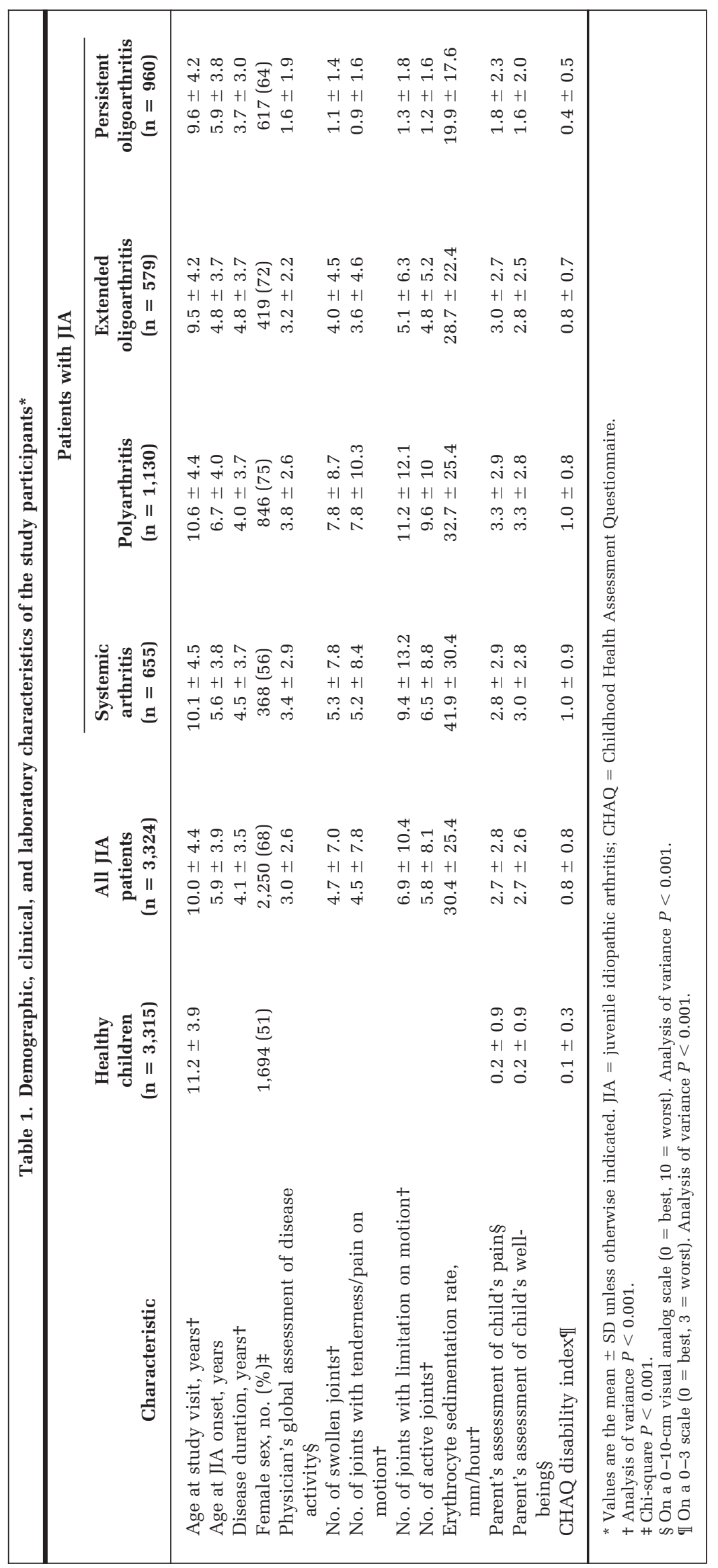


the attending physician: number of joints with swelling, number of joints with tenderness/pain on passive motion, number of joints with limited range of motion, number of joints with active arthritis (21), and physician's global assessment of the overall disease activity on a doubleanchored 10-cm VAS (with anchors of 0 [inactive] and 10 [very severe]). The laboratory indicator of systemic inflammation was erythrocyte sedimentation rate (ESR).

Statistical analysis. Descriptive statistics were reported in terms of means and SDs for the continuous variables and in terms of absolute frequencies and percentages for the categorical variables. Statistical tests included Student's $t$-test or Mann-Whitney U test, 1-way analysis of variance with Scheffe's test for post hoc comparisons, chi-square test, or Fisher's exact test as appropriate. Spearman's rank order correlation coefficients were calculated to evaluate the relationship between the clinical measures and the summary scores of the CHQ, the PhS or the PsS: correlations $>0.7$ were considered high, correlations ranging from $0.4-0.7$ were considered moderate, and correlations $<0.4$ were considered low. Multivariate logistic regression was used to find relevant independent explanatory variables for the physical and psychosocial domains of HRQOL. Cut points for PhS and PsS scores were $<30$ $(<2$ SDs of the mean of healthy children; poorer HRQOL) and $\geq 30$ (better HRQOL). We chose $<2$ SDs as cutoff to concentrate on the patients who had the poorest HRQOL as measured by the CHQ. Possible explanatory variables assessed were all those shown in Table 1 dichotomized according to the best threshold obtained from the receiver operating characteristic (ROC) curve analysis (22). Dichotomization of explanatory variables has the advantage of providing clinically meaningful odds ratios (ORs) with $95 \%$ confidence intervals (95\% CIs). Statistical significance of the variables in the models was tested by means of the likelihood ratio test. All statistical tests were 2 -sided. It was anticipated that, owing to the large size of the study sample, all comparisons between patients and healthy children would be statistically significant and therefore only $P$ values less than 0.001 were considered for the qualitative interpretation of the data. The statistical package Statistica (StatSoft, Tulsa, OK) was used for univariate analyses and Stata, release 7 (StataCorp, College Station, TX) was used for multivariate analyses.

\section{RESULTS}

Of the 6,806 potentially eligible participants, 6,639 $(3,324$ with JIA and 3,315 healthy children) were included in this study; the remaining 167 were excluded because they were $>18$ years of age at the time of the study visit. Data for these 6,639 children were collected from the following 32 countries: Argentina $(\mathrm{n}=117)$, Austria $(\mathrm{n}=131)$, Belgium $(\mathrm{n}=203)$, Brazil $(\mathrm{n}=486)$, Bulgaria $(\mathrm{n}=129)$, Chile $(\mathrm{n}=$ 121), Croatia $(\mathrm{n}=139)$, Czech Republic $(\mathrm{n}=148)$, Denmark $(\mathrm{n}=134)$, Finland $(\mathrm{n}=162)$, France $(\mathrm{n}=495)$, Georgia $(\mathrm{n}=110)$, Germany $(\mathrm{n}=199)$, Greece $(\mathrm{n}=134)$, Hungary $(\mathrm{n}=125)$, Israel $(\mathrm{n}=150)$, Italy $(\mathrm{n}=1,189)$, Korea $(\mathrm{n}=203)$, Latvia $(\mathrm{n}=141)$, Mexico $(\mathrm{n}=182)$, The Netherlands $(\mathrm{n}=187)$, Norway $(\mathrm{n}=152)$, Poland $(\mathrm{n}=30)$,
Portugal $(\mathrm{n}=120)$, Russia $(\mathrm{n}=142)$, Serbia and Montenegro $(n=133)$, Slovakia $(n=121)$, Spain $(n=152)$, Sweden $(\mathrm{n}=130)$, Switzerland $(\mathrm{n}=151)$, Turkey $(\mathrm{n}=146)$, and United Kingdom $(\mathrm{n}=477)$. In each country, a roughly equivalent number of patients with JIA and healthy children were collected.

The main demographic, clinical, and laboratory features of the patients with JIA and the comparison sample of healthy children are shown in Table 1. According to the ILAR criteria, $655(19.7 \%)$ of the patients with JIA had systemic arthritis, $1,130(34.0 \%)$ had polyarthritis, 579 $(17.4 \%)$ had extended oligoarthritis, and $960(28.9 \%)$ had persistent oligoarthritis. At the time of the study visit, patients with JIA were, on average, younger than the sample of healthy peers (mean \pm SD age $10 \pm 4.4$ years and $11.2 \pm 3.9$ years, respectively; $P<0.001$ ); this statistical difference was thought to be clinically irrelevant, being a consequence of the big sample size. Among patients with JIA, those with systemic and polyarthritis were older (mean \pm SD age at visit $10.5 \pm 4.4$ years) than those with oligoarthritis ( $9.6 \pm 4.2$ years; $P<0.0001)$. As expected, the female frequency was higher among patients with JIA than in the sample of healthy children $(68 \%$ and $51 \%$, respectively; $P<0.001$ ); when we compared the HRQOL of the sample of healthy females with that of healthy males, we did not find any difference for both the $\mathrm{PhS}$ and the PsS ( $P=0.2$ and $P=0.1$, respectively). Patients with polyarthritis had the greatest extent and severity of joint disease, followed by those with systemic arthritis and extended oligoarthritis; patients with persistent oligoarthritis had much less severe joint disease than the other subtypes. Patients with systemic JIA displayed a more pronounced systemic inflammation, as expressed by ESR.

The mean \pm SD CHAQ score was $0.8 \pm 0.8$ for the entire JIA cohort and $0.1 \pm 0.3$ for the sample of healthy children $(P<0.0001)$. The most impaired CHAQ areas (score $>0.7)$ in patients with JIA were dressing, activities, and reaching (data not shown). CHAQ scores were comparable in patients with systemic arthritis, polyarthritis, and extended oligoarthritis, but were much lower in patients with persistent oligoarthritis. The mean \pm SD parents' rating of the intensity of children's pain was $2.7 \pm 2.8$ in the entire JIA cohort and $0.2 \pm 0.9$ in the sample of healthy children $(P<0.0001)$. The mean \pm SD parents' rating of the children's overall well-being was $2.7 \pm 2.6$ in the entire JIA cohort and $0.2 \pm 0.9$ in the sample of healthy children $(P<0.0001)$.

Assessment of HRQOL. The CHQ was completed by the mother in $79 \%$ of cases and by the father or guardian in $21 \%$ of cases. The mean \pm SD PhS score of the CHQ was significantly lower in patients with JIA than in the sample of healthy children $(44.5 \pm 10.6$ and $54.6 \pm 4.0$, respectively; $P<0.0001$ ). Likewise, the mean PsS score of the CHQ was significantly lower in patients with JIA than in healthy children $(47.6 \pm 8.7$ and $51.9 \pm 7.52$, respectively; $P<0.0001$ ). The mean values of the 15 subscales of the CHQ and the 2 summary scores, the PhS and the PsS, in the 4 JIA subtypes are illustrated in Figure 1. In Figure 1, the vertical bar at the top of each column represents a 


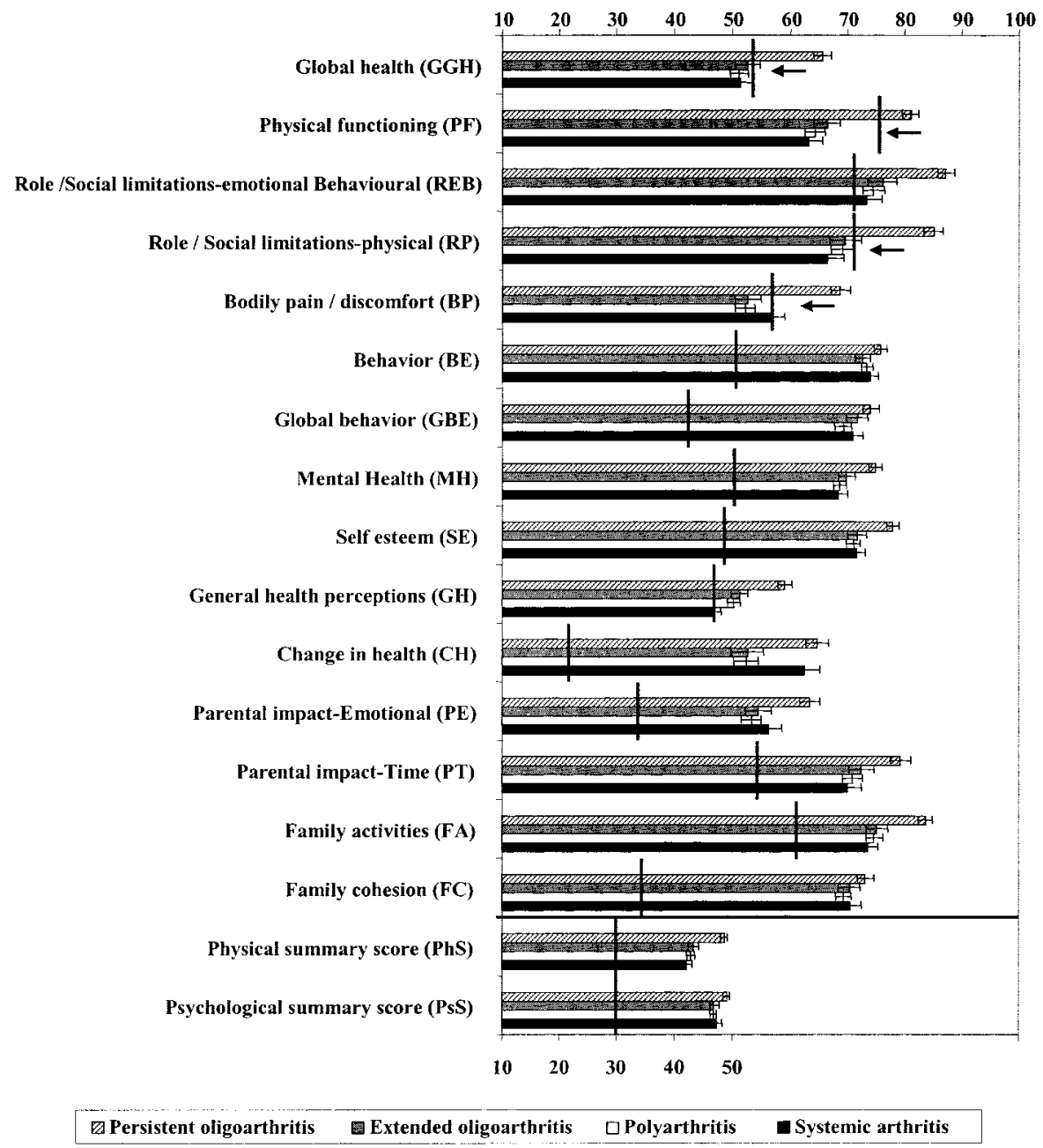

Figure 1. Mean and 95\% confidence intervals of the 15 subscales (range 0-100) and the 2 summary scores (norm-based values with mean \pm SD of $50 \pm 10$ ) of the Child Health Questionnaire (CHQ). Higher scores indicate better health. Vertical bars represent -2 SD of the mean of healthy children. Arrows indicate the 4 CHQ health concepts (global health, physical functioning, role social limitations: physical, and bodily pain/discomfort) that are $<2$ SDs of the mean of healthy children. Analysis of variance $P$ values for comparisons of the 4 juvenile idiopathic arthritis subtypes are $<0.001$ for all CHQ subscales and summary scores.

value that is $<2$ SDs of the means of the sample of healthy children.

Patients with persistent oligoarthritis showed better levels of HRQOL in all CHQ subscales and in both summary measures compared with patients with the other subtypes. The level of HRQOL in all CHQ domains was similar across patients with systemic arthritis, polyarthritis, and extended oligoarthritis; in these 3 subtypes the most impaired CHQ health concepts $(<2$ SDs of the means of the sample of healthy children) were global health, physical functioning, role social limitation (physical), and bodily pain/discomfort (see arrows in Figure 1).

Relationship between HRQOL and physical disability. The mean values and 95\% CIs of the CHQ PhS and PsS in patients with JIA and in the sample of healthy children are shown in Figure 2 divided into 2 groups according to the best threshold of the CHAQ (score = 1) obtained from the ROC curves analysis. There were 2,045 JIA patients (71\%) with a CHAQ score $\leq 1$ and 838 JIA patients (29\%) with a CHAQ score $>1$; all healthy children had a CHAQ score $<1$ (mean \pm SD score $0.1 \pm 0.3$ ). This analysis demonstrated that both summary measures of the CHQ discriminate well among patients with JIA with different levels of disability and between healthy children and patients with JIA, irrespective of the level of disability. However, the discriminative ability of the $\mathrm{PhS}$ was superior to that of the PsS because patients with JIA had less impairment in psychosocial well-being than in physical well-being, both in general and in relation to the degree of physical disability. This is clearly detectable in Figure 2, where patients with JIA with the higher level of disability are $>1$ SD below the mean of the sample of healthy children for the CHQ PhS, but not for the PsS.

Correlation between HRQOL and JIA severity measures. The Spearman correlations between the CHQ PhS and the CHAQ score ( $\mathrm{r}=-0.63)$, the parent's assessment 

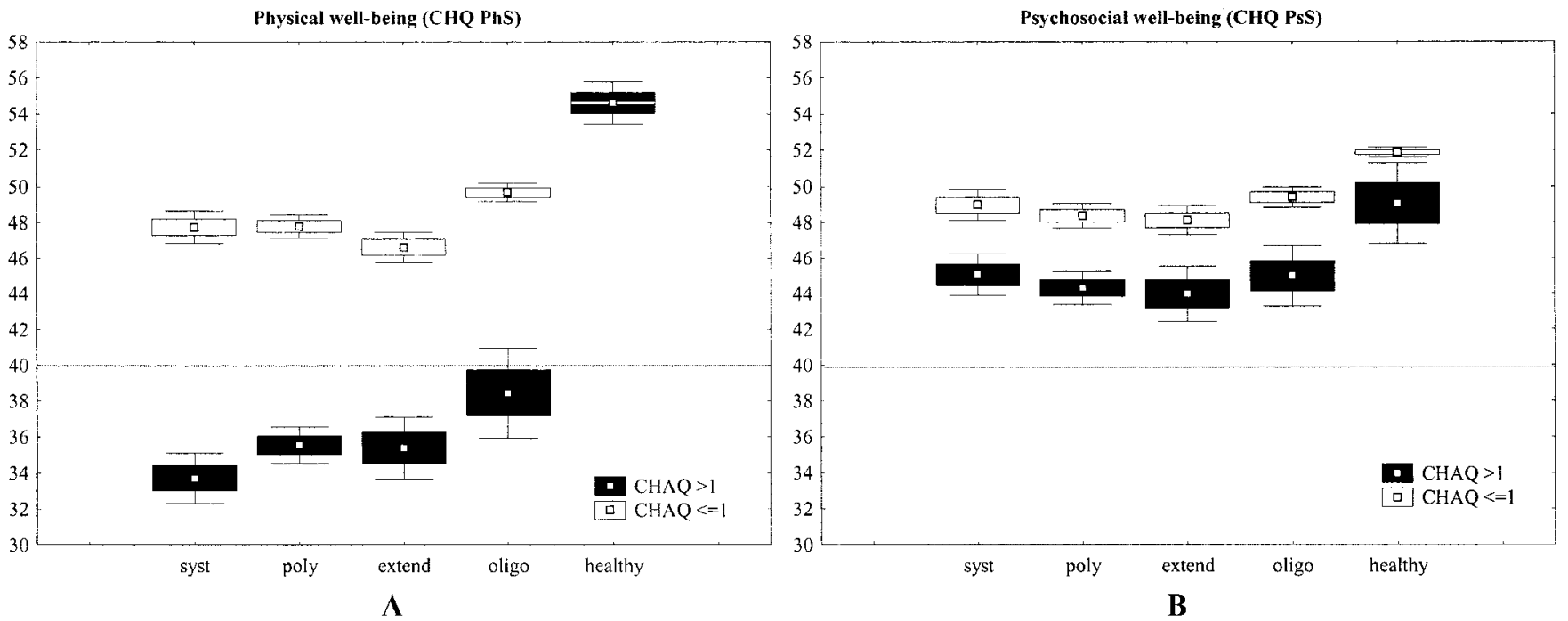

Figure 2. Mean values and 95\% confidence intervals A, of the physical summary score (PhS) and B, psychosocial summary score (PsS) of the Child Health Questionnaire (CHQ) in patients with juvenile idiopathic arthritis and in healthy children categorized according to the presence of a Childhood Health Assessment Questionnaire (CHAQ) score $\leq 1$ or $>1$. The horizontal dotted line refers to a PhS or PsS 1 SD below the mean of healthy children. Of note, in A the boxes for healthy children with CHAQ scores $\leq 1$ or $>1$ are overlapping. Syst $=$ systemic arthritis; poly $=$ polyarthritis; extend $=$ extended oligoarthritis; oligo $=$ persistent oligoarthritis.

of the intensity of the child's pain $(r=-0.63)$, the parent's assessment of the child's overall well-being $(\mathrm{r}=-0.61)$, the physician's global assessment of the overall disease activity $(\mathrm{r}=-0.52)$, the number of joints with tenderness/ pain on passive motion $(\mathrm{r}=-0.45)$, and the number of active joints $(\mathrm{r}=-0.42)$ were in the moderate range, whereas the correlations with the number of joints with limited range of motion $(\mathrm{r}=-0.40)$, the number of swollen joints $(r=-0.36)$, and ESR $(r=-0.36)$ were in the low range. All Spearman's correlations between the CHQ PsS and JIA severity measures were poor $(\mathrm{r}=-0.13,0.36)$.

The better relationship of the physical component of HRQOL with disease-centered measures was confirmed after categorization of the measures into increasing levels of severity. As shown in Figure 3, although both summary

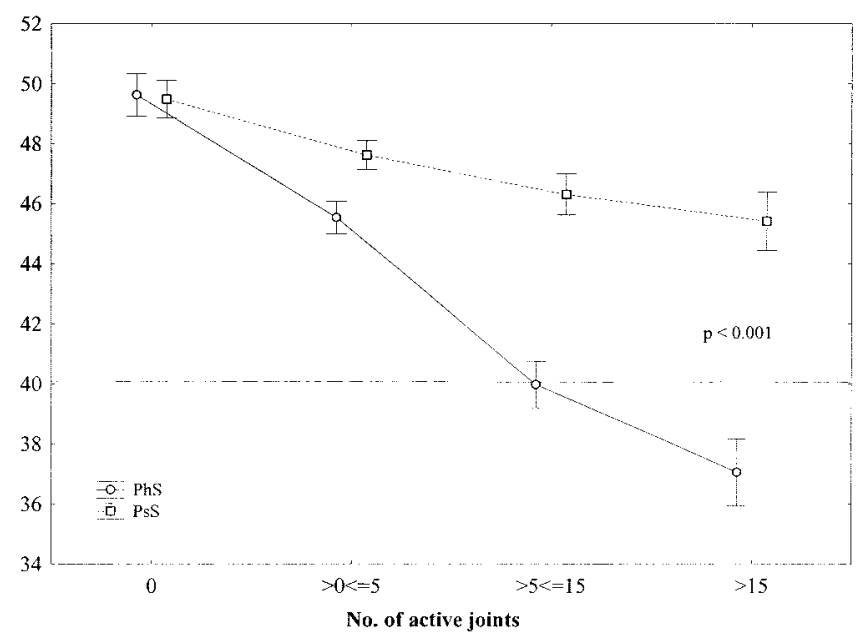

Figure 3. Relationship between the physical summary score (PhS) and psychosocial summary score (PsS) of the Child Health Questionnaire and the number of joints with active arthritis categorized in 4 levels of severity. The horizontal dotted line refers to the PhS or PsS 1 SD below the mean of healthy children. scores demonstrated a progressive decline with increasing number of active joints, the effect was much more pronounced on the PhS, with patients with $>5$ active joints having a $\mathrm{PhS}>1$ SD below the mean of healthy children. Similar findings were obtained for the other JIA severity measures (data not shown).

Analysis of determinants of poor HRQOL. Dichotomization of CHQ scores in patients with JIA according to the values observed in healthy children demonstrated that 372 $(13 \%)$ and $848(29 \%)$ patients had a $\mathrm{PhS}<2$ SDs and $<1$ SD below the mean of the sample of healthy children, respectively, and that $105(4 \%)$ and $562(19 \%)$ patients had a PsS $<2$ SDs and $<1$ SD below the mean of healthy children, respectively.

In univariate analyses, we found that all clinical measures of JIA severity (physician's and parent's global assessments, joint counts, CHAQ score, and ESR) were significantly correlated with the dichotomized $\mathrm{PhS}$ and PsS $(P<0.0001$ for all variables). Of the demographic and clinical variables reported in Table 1, only disease duration and JIA subtype were significantly associated with both PhS and PsS.

All variables that were significantly associated with the 2 dichotomized outcomes in univariate analyses, plus sex, were entered in the logistic regression procedures. The best fitting models obtained from the evaluation of the determinants of a poor HRQOL, as measured by the 2 summary measures of the CHQ, are shown in Table 2 . The strongest determinants of a poor physical well-being (PhS $<2$ SDs of the mean of healthy children) were a CHAQ score $>1$ (OR 5.1, 95\% CI 3.8-7), a parent's rating of the child's pain intensity $>3.4$ (OR $2.5,95 \%$ CI $1.8-3.5$ ), a parent's assessment of the child's overall well-being $>3.7$ (OR 2.2, 95\% CI 1.6-3.1), ESR $>32$ mm/hour (OR 2.1, 95\% CI 1.6-2.8), and a physician's global assessment of disease 


\begin{tabular}{|c|c|c|}
\hline & \multicolumn{2}{|c|}{ Outcomes } \\
\hline & $\begin{array}{l}\text { CHQ PhS } \\
(n=2,575)\end{array}$ & $\begin{array}{c}\text { CHQ PsS } \\
(n=2,875)\end{array}$ \\
\hline $\begin{array}{l}\text { HRQOL determinants } \\
\text { CHAQ disability index }(>1) \\
\text { Parent's assessment of child's pain }(<3.4) \\
\text { Parent's global assessment of child's well-being }(<3.7) \\
\text { Erythrocyte sedimentation rate }(<32 \text { mm/hour) } \\
\text { Physician's global assessment of disease activity }(<3.4) \\
\text { Sex (female) } \\
\text { Pearson's } \chi^{2} \text { goodness-of-fit test, } P \\
\text { Area under ROC curve }\end{array}$ & $\begin{array}{c}5.1(3.8-7.0) \dagger \\
2.5(1.8-3.5) \dagger \\
2.2(1.6-3.1) \dagger \\
2.1(1.6-2.8) \dagger \\
1.6(1.1-2.1) \S \\
0.7(0.6-1.0) \mathbb{I} \\
0.5 \\
0.87\end{array}$ & $\begin{array}{c}0.8(0.5-1.2) \# \\
0.4 \\
0.74\end{array}$ \\
\hline $\begin{array}{l}\text { * Values are the odds ratio ( } 95 \% \text { confidence interval) unless othern } \\
\text { been dichotomized according to scores }<30(<2 \text { SDs below the } m \\
\text { values refer to the likelihood ratio test. HRQOL }=\text { health-related qu } \\
\text { score; PsS = psychosocial summary score; CHQ = Child Health } \\
\text { Health Assessment Questionnaire; ROC = receiver operating chara } \\
+P<0.0001 . \\
¥ P=0.006 . \\
\S P=0.007 . \\
\mathbb{I} P=0.05 . \\
\# P=0.21 .\end{array}$ & $\begin{array}{l}\text { indicated. The } \\
\text { an of healthy chil } \\
\text { ity of life; } \mathrm{PhS}= \\
\text { uestionnaire; } \mathrm{CH} \\
\text { eristic curve. }\end{array}$ & $\begin{array}{l}\text { hS and PsS have } \\
\text { lren) and } \geq 30 . P \\
\text { hysical summary } \\
\mathrm{Q}=\text { Childhood }\end{array}$ \\
\hline
\end{tabular}

activity $>3.4$ (OR 1.6, 95\% CI 1.1-2.1). The strongest determinants of a poor psychosocial well-being (PsS $<2$ SDs of the mean of healthy children) were a parent's rating of the child's pain intensity $>3.4$ (OR 4.7, 95\% CI 2.9-7.6) and a CHAQ score $>1$ (OR 1.8, 95\% CI 1.2-2.8).

\section{DISCUSSION}

We investigated the HRQOL of a large cohort of children with JIA followed in several different countries worldwide and compared the results with those obtained in healthy peers of similar age who come from the same geographic area. These data were obtained in the context of a study, conducted by PRINTO, that was aimed at translating and cross-culturally validating the American English version of the CHQ (and CHAQ) in 32 different languages $(15,16)$. It was anticipated that, owing to the large size of the study sample, all comparisons between patients and healthy children would be statistically significant. The results of comparative analyses should, therefore, be interpreted qualitatively rather than quantitatively.

Our results indicate that, on average, patients with JIA have a poorer HRQOL as compared with healthy peers in both physical and psychosocial domains, with physical health being more affected. The areas of HRQOL most affected by JIA $(<2$ SDs of the mean of healthy children) were global health, physical functioning, role social limitation (physical), and bodily pain/discomfort. The impact on physical functioning and the high level of bodily pain were expected because the disease produces pain and functional limitation in the affected joints, which may limit children's mobility and activities. Also the impairment in general health perceptions and parent emotional subscales of the CHQ would suggest that parents of patients with JIA are mostly concerned with their child's overall health and resistance/susceptibility to sickness, and they are emotionally distressed about their child's physical, emotional, mental, and social functioning. Notably, these HRQOL areas were also found to be mostly affected in children and adolescents with systemic lupus erythematosus (23). The mean values of the behavior, global behavior, mental health, self-esteem, and family cohesion subscales were close to those observed in the control group. These findings are reassuring because they mean that, on average, children with JIA had no behavioral problems, had the ability to get along with others, were perceived by their parents as having no anxiety or depression, and did not have relevant troubles with body image and social confidence, and that the disease did not affect the family relationships and cohesion. However, it should also be noted that the measurement error of proxy report for internal states might be considerable, and therefore it is possible that a study with pediatric patient self-reported psychosocial functioning might have different results.

When patients with JIA were divided according to ILAR category, we found that those with persistent oligoarthritis had, on average, a better HRQOL than those with the other subtypes in all domains; the HRQOL of patients with systemic arthritis, polyarthritis, and extended oligoarthritis was similar in these 3 subtypes. Taken together, these findings are in keeping with the general view that persistent oligoarthritis is the most benign form of JIA and suggest that the other main disease subtypes have a similar impact on HRQOL.

As could be expected, when classified by level of physical disability, great impairment was observed in physical well-being for patients with JIA relative to their psychosocial well-being (Figure 2). While most patients with a CHAQ score $>1$, indicating moderate-to-severe functional impairment (24), had a CHQ PhS $<1$ SD of the mean of healthy children, all patients, irrespective of their CHAQ score, had a CHQ PsS within the normal range for healthy 
children. These findings may lead one to postulate that the effects of physical disability on physical functioning are profound and long lasting, whereas social, mental, emotional, and behavioral health my adjust better over time to the burden of the chronic disease. However, it should also be noted that the finding that the CHQ PhS was superior to the PsS might also be due to the considerable construct overlap between the proxy-reported CHQ PhS and the CHAQ.

The profound impact of functional impairment on physical well-being was strengthened by the results of multivariate analysis, which showed that a CHAQ score $>1$ was the strongest determinant of poorer HRQOL in the PhS of the CHQ. The intensity of the child's pain was the major predictor of poorer psychosocial well-being. These findings underscore the importance of preventing physical disability and controlling pain to preserve HRQOL of patients with JIA. It is worth noting that ESR was the sole objective measure of inflammation that predicted the HRQOL.

Our results are not easily comparable with those of previous investigations of HRQOL in children with JIA due to differences in the study design, the predictors assessed, and the instruments used to measure HRQOL. In a previous study, Ruperto et al $(24,25)$ measured the HRQOL in a cohort of adults who had JIA in childhood and found that a very high percentage of these adults classified themselves as having a high quality of life, and that only ESR was predictive of future HRQOL. Aasland et al (26) reported that long-term psychosocial outcome was favorable in most patients and that psychosocial functioning at followup was predicted by chronic family difficulties and correlated with physical disability, as measured by the CHAQ. A significant relationship between clinical depression and anxiety on psychological testing and the degree of disability was found by David et al (27). In a populationbased study, Peterson et al (28) reported that their JIA cohort perceived poorer health, less energy, more bodily pain, and more limitation in physical functioning compared with healthy children. Foster et al (29) recorded significantly worse scores than healthy controls in all physical scales and in the emotional role scale of the HRQOL measure in adults who had JIA. A strong influence of pain on well-being was observed by Sällfors et al (30), with as many as $55.6 \%$ of children not attending or only sometimes attending physical education classes due to joint pain. Arkela-Kautiainen et al (31) found lower HRQOL in all physical components in patients with active disease than in those in remission or in children. In the mental component of HRQOL, no differences were seen between the groups. The patient's global assessment on a VAS explained both the physical and mental component of the HRQOL. Brunner and Giannini (32) reported that children's HRQOL significantly decreased with increasing disability. Taken together, the results of these studies are in keeping with those of our analysis in demonstrating that children with JIA have a greater impairment in physical well-being than in psychosocial health, and that physical disability and pain are important determinants of HRQOL.

We must acknowledge the study limitations due to its cross-sectional nature, the proxy-reported evaluation of
HRQOL, and the fact the CHQ summary measures calculations were based on US standards (12). Because JIA is often characterized by periods of exacerbation and quiescence, there can be remission phases in which patients feel well and exacerbation phases in which they can have symptoms of acute inflammation. It is, therefore, difficult to determine a causal relationship in a cross-sectional study, because there is doubt about the timing of the relationship. Furthermore, we did not collect information about the patients' ethnicity and socioeconomic background, which may affect HRQOL. However, the wide geographic area of patients' enrollment ensures that most of the non-disease-related factors were incorporated and that, therefore, our results are likely generalizable to the majority of JIA populations. A separate report evaluates if patients coming from various geographic areas have differences in their HRQOL (33).

In summary, we found that patients with JIA have a significant impairment of their HRQOL compared with healthy peers, particularly in the physical domain. Physical well-being was mostly affected by the level of functional impairment, whereas the intensity of pain had the greatest influence on psychosocial well-being. These findings indicate that prevention of physical disability and pain control are the most important objectives of therapeutic interventions in JIA.

\section{ACKNOWLEDGMENTS}

We are indebted to the PRINTO national coordinators who managed the work of the pediatric rheumatology centers of each country for data collection, and to the families of the patients with JIA and of healthy children that allowed us to study their children. Additional PRINTO national coordinators who participated in the quality of life project are as follows: Carmen De Cunto, MD, Buenos Aires, Argentina; Christian Huemer, MD, Vienna, Austria; Dimitrina Mihaylova, MD, PhD, Sofia, Bulgaria; Marta Miranda, MD, Santiago, Chile; Miroslav Harjacek, MD, Zagreb, Croatia; Susan Nielsen, MD, Copenhagen, Denmark; Kharaman Pagava, MD, DSc, Prof, Tblisi, Georgia; Ivan Foeldvari, MD, Hamburg, Hans-Iko Huppertz, Prof. DrMed, Bremen, Germany; Zsolt Balogh, MD, Prof, Budapest, Hungary; Ingrida Rumba, MD, PhD, Prof, Riga, Latvia; Ruben Burgos-Vargas, MD, Mexico City, Mexico; Wietse Kuis, MD, PhD, Utrecht, The Netherlands; Anna-Maria Romicka, MD, Prof, Warsaw, Poland; José António Melo-Gomes, MD, Lisbon, Portugal; Richard Vesely, MU Dr, Kosice, Slovakia; Boel Andersson Gare, MD, PhD, Jönköping, Sweden; Patricia Woo, London, UK; and Gordana Susic, MD, Belgrade, Yugoslavia.

\section{AUTHOR CONTRIBUTIONS}

Dr. Ruperto had full access to all of the data in the study and takes responsibility for the integrity of the data and the accuracy of the data analysis.

Study design. Dr. Ruperto.

Acquisition of data. Drs. Oliveira, Castell, Malattia, Prieur, SaadMagalhães, Murray, Bae, Joos, Foeldvari, Duarte-Salazar, Wulffraat, Lahdenne, Dolezalova, de Inocencio, Kanakoudi-Tsakalidou, Hofer, Nikishina, Ozdogan, and Hashkes. 
Analysis and interpretation of data. Drs. Ravelli, Pistorio, Ms Landgraf, and Drs. Martini, and Ruperto.

Manuscript preparation. Drs. Ravelli, Pistorio, Murray, Lahdenne, Dolezalova, de Inocencio, Kanakoudi-Tsakalidou, Hofer, Hashkes, Ms Landgraf, and Drs. Martini, and Ruperto.

Statistical analysis. Drs. Pistorio, and Ruperto and Ms Landgraf.

\section{REFERENCES}

1. Duffy CM. Health outcome in pediatric rheumatic diseases. Curr Opin Rheumatol 2004;16:102-8.

2. Ravelli A. Toward an understanding of the long-term outcome of juvenile idiopathic arthritis. Clin Exp Rheumatol 2004;22: $271-5$.

3. Viola S, Felici E, Magni-Manzoni S, Pistorio A, Buoncompagni A, Ruperto N, et al. Development and validation of a clinical index for assessment of long-term damage in juvenile idiopathic arthritis. Arthritis Rheum 2005;52:2092-102.

4. Duffy CM. Measurement of health status, functional status, and quality of life in children with juvenile idiopathic arthritis: clinical science for the pediatrician. Pediatr Clin North Am 2005;52:359-72, v.

5. Tucker LB. Whose life is it anyway? Understanding quality of life in children with rheumatic diseases. J Rheumatol 2000; 27:8-11.

6. Burgos-Vargas R. Assessment of quality of life in children with rheumatic disease. J Rheumatol 1999;26:1432-5.

7. Coulton CJ, Zborowsky E, Lipton J, Newman AJ. Assessment of the reliability and validity of the Arthritis Impact Measurement Scales for children with juvenile arthritis. Arthritis Rheum 1987;30:819-24.

8. Howe S, Levinson J, Shear E, Hartner S, McGirr G, Schulte M, et al. Development of a disability measurement tool for juvenile rheumatoid arthritis: the juvenile arthritis functional assessment report for children and their parents. Arthritis Rheum 1991;34:873-80.

9. Singh G, Athreya BH, Fries JF, Goldsmith DP. Measurement of health status in children with juvenile rheumatoid arthritis. Arthritis Rheum 1994;37:1761-9.

10. Wright FV, Law M, Crombie V, Goldsmith CH, Dent P. Development of a self-report functional status index for juvenile rheumatoid arthritis. J Rheumatol 1994;21:536-44.

11. Duffy CM, Arsenault L, Duffy KN, Paquin JD, Strawczynski H. The Juvenile Arthritis Quality of Life Questionnaire: development of a new responsive index for juvenile rheumatoid arthritis and juvenile spondyloarthritides. J Rheumatol 1997; $24: 738-46$

12. Landgraf JM, Abetz L, Ware JE. The CHQ user's manual. 1st ed. Boston: The Health Institute, New England Medical Center; 1996.

13. Varni JW, Seid M, Knight TS, Burwinkle T, Brown J, Szer IS. The PedsQL ${ }^{\mathrm{TM}}$ in pediatric rheumatology: reliability, validity, and responsiveness of the Pediatric Quality of Life Inventory $^{\mathrm{TM}}$ generic core scales and rheumatology module. Arthritis Rheum 2002;46:714-25.

14. Ruperto N, Martini A. International research networks in pediatric rheumatology: the PRINTO perspective. Curr Opin Rheumatol 2004;16:566-70.

15. Martini A, Ruperto N, and the Paediatric Rheumatology International Trials Organization (PRINTO). Quality of life in juvenile idiopathic arthritis patients compared to healthy children. Clin Exp Rheumatol 2001;19 Suppl 23:S1-172.

16. Ruperto N, Ravelli A, Pistorio A, Malattia C, Cavuto S, GadoWest L, et al. Cross-cultural adaptation and psychometric evaluation of the Childhood Health Assessment Questionnaire (CHAQ) and the Child Health Questionnaire (CHQ) in 32 countries: review of the general methodology. Clin Exp Rheumatol 2001;19 Suppl 23:S1-9.
17. Guillemin F, Bombardier C, Beaton D. Cross-cultural adaptation of health-related quality of life measures: literature review and proposed guidelines. J Clin Epidemiol 1993;46: 1417-32.

18. Giannini EH, Ruperto N, Ravelli A, Lovell DJ, Felson DT, Martini A. Preliminary definition of improvement in juvenile arthritis. Arthritis Rheum 1997;40:1202-9.

19. Ruperto N, Ravelli A, Falcini F, Lepore L, de Sanctis R, Zulian F, et al, and the Italian Pediatric Rheumatology Study Group. Performance of the preliminary definition of improvement in juvenile chronic arthritis patients treated with methotrexate. Ann Rheum Dis 1998;57:38-41.

20. Petty RE, Southwood TR, Baum J, Bhettay E, Glass DN, Manners P, et al. Revision of the proposed classification criteria for juvenile idiopathic arthritis: Durban, 1997. J Rheumatol 1998;25:1991-4.

21. Cassidy JT, Levinson JE, Bass JC, Baum J, Brewer EJ Jr, Fink CW, et al. A study of classification criteria for a diagnosis of juvenile rheumatoid arthritis. Arthritis Rheum 1986;29:27481.

22. Metz CE. Basic principles of ROC analysis. Semin Nucl Med 1978;8:283-98.

23. Ruperto N, Buratti S, Duarte-Salazar C, Pistorio A, Reiff A, Bernstein B, et al. Health-related quality of life in juvenileonset systemic lupus erythematosus and its relationship to disease activity and damage. Arthritis Rheum 2004;51:45864

24. Ruperto N, Ravelli A, Levinson JE, Shear ES, Murray K, Link Tague B, et al. Long-term health outcomes and quality of life in American and Italian inception cohorts of patients with juvenile rheumatoid arthritis. II. Early predictors of outcome. J Rheumatol 1997;24:952-8.

25. Ruperto N, Levinson JE, Ravelli A, Shear ES, Link Tague B, Murray K, et al. Long-term health outcomes and quality of life in American and Italian inception cohorts of patients with juvenile rheumatoid arthritis. I. Outcome status. J Rheumatol 1997;24:945-51.

26. Aasland A, Flato B, Vandvik IH. Psychosocial outcome in juvenile chronic arthritis: a nine-year follow-up. Clin Exp Rheumatol 1997;15:561-8.

27. David J, Cooper C, Hickey L, Lloyd J, Dore C, McCullough C, et al. The functional and psychological outcomes of juvenile chronic arthritis in young adulthood. Br J Rheumatol 1994; 33:876-81

28. Peterson LS, Mason T, Nelson AM, O'Fallon WM, Gabriel SE. Psychosocial outcomes and health status of adults who have had juvenile rheumatoid arthritis: a controlled, populationbased study. Arthritis Rheum 1997;40:2235-40.

29. Foster HE, Marshall N, Myers A, Dunkley P, Griffiths ID. Outcome in adults with juvenile idiopathic arthritis: a quality of life study. Arthritis Rheum 2003;48:767-75.

30. Sallfors C, Hallberg LR, Fasth A. Well-being in children with juvenile chronic arthritis. Clin Exp Rheumatol 2004;22:12530.

31. Arkela-Kautiainen M, Haapasaari J, Kautiainen H, Vilkkumaa I, Malkia E, Leirisalo-Repo M. Favourable social functioning and health related quality of life of patients with JIA in early adulthood. Ann Rheum Dis 2005;64:875-80.

32. Brunner HI, Giannini EH. Health-related quality of life in children with rheumatic diseases. Curr Opin Rheumatol 2003;15:602-12.

33. Gutierrez-Suarez R, Pistorio A, Cespedes Cruz A, Norambuena X, Flato B, Rumba I, et al, and the PRINTO Multinational Quality of Life Cohort Study. Health-related quality of life of patients with juvenile idiopathic arthritis coming from 3 different geographic areas. Rheumatology (Oxford) 2006. E-pub ahead of print. 